\title{
Variation in dental remains from Dmanisi, Georgia
}

\author{
P. James MACALUSO, Jr*1 \\ ${ }^{1}$ Department of Anthropology, Binghamton University, Binghamton, NY 13902-6000, USA
}

Receivsed 1 May 2009; accepted 23 June 2009

\begin{abstract}
Observable differences among craniomandibular specimens from Dmanisi, Republic of Georgia have resulted in controversy regarding the number of represented taxa. In this study, the hominin dental remains from Dmanisi are analyzed to help determine whether the variation present in the Georgian assemblage likely reflects interspecific or intraspecific variation, including sexual dimorphism. Metric variation is assessed with resampling methodology by comparing the Dmanisi teeth with reference samples of extant hominoids. Comparisons were also made between the variation observed in the Georgian sample and that of Paranthropus boisei. The results provide evidence for the taxonomic homogeneity of the D211/D2282 and D2735/D2700 skulls. Whether D2600 should be included within this sample or considered distinct is less clear as the distal molar crown dimensions of this robust specimen are notably larger than the other Georgian fossils. Nonetheless, it is argued that the metric size variation expressed by the Dmanisi dental sample, including D2600, is insufficient to reject the null hypothesis of a single species.
\end{abstract}

Key words: Intraspecific variation, Early Homo, Dental metrics, Randomization

\section{Introduction}

The stratified deposits at Dmanisi in the Georgian Caucasus have produced large quantities of well-preserved faunal remains, lithic artifacts, and hominin fossils. The hominin inventory from Dmanisi now includes four crania, four mandibles, and their associated teeth (Gabunia and Vekua, 1995; Gabunia et al., 2000, 2002a, 2002b; Vekua et al., 2002; Lordkipanidze et al., 2005, 2006), as well as numerous postcranial elements (Lordkipanidze et al., 2007). A combination of geological and paleontological evidence dates the fossil material to c. 1.77 million years ago (Rightmire et al., 2006; Lordkipanidze et al., 2007). Stratigraphic and sedimentological data seem to indicate that all of the Dmanisi fossils accumulated over a very short time interval, perhaps as little as $10 \mathrm{kyr}$ (Gabunia et al., 2001; Lordkipanidze et al., 2006) or possibly during a single catastrophic event (de Lumley et al., 2008), and thus all the fossils may be regarded as essentially contemporary. However, a recent paleomagnetic study of the volcanic deposits suggests that although the age of the site could span several ten thousands of years, a much wider period of hundreds of thousands of years cannot be excluded (Calvo-Rathert et al., 2008).

In describing the cranial specimens from Dmanisi, Gabunia and colleagues (Gabunia et al., 2000; Vekua et al., 2002; Lordkipanidze et al., 2005) concluded that the observed variability is representative of a single hominin population

* Correspondence to: P. James Macaluso, Jr, Department of Anthropology, Binghamton University (SUNY), Binghamton, NY 139026000, USA.

E-mail: p.james.macaluso@hotmail.com

Published online 28 August 2009

in J-STAGE (www.jstage.jst.go.jp) DOI: 10.1537/ase090501 displaying size variation due to sexual dimorphism, as well as developmental and individual variation. A more comprehensive treatment of the hominin skulls provided a similar conclusion (Rightmire et al., 2006). Rightmire et al. (2006) demonstrated that although the Georgian hominins display variation related to growth status and sexual dimorphism, the individuals from Dmanisi represent one paleodeme. Statistical (randomization) analyses have also shown that the level of dimorphism displayed by the Dmanisi crania is not excessive relative to that observed in some extant apes and modern humans (Macaluso et al., 2004; Lee, 2005; Lorenzo et al., 2005).

These conclusions have not gone unchallenged, however, and other researchers have suggested that the morphological variation among the Dmanisi crania is excessive for a single species and reflects intertaxic rather than intrapopulational variation (Schwartz, 2000; Schwartz and Tattersall, 2003). Gabunia and colleagues (Gabunia et al., 2002a, 2002b) also discuss the significance of the morphological variation displayed among the Georgian mandibular remains. Although it has been suggested that the dissimilarity between D2600 and D211 reflects marked sexual dimorphism (Gabunia et al., 2002a), Gabunia and colleagues did not find this argument entirely convincing (Gabunia et al., 2002b). Furthermore, a recent study demonstrated that the Georgian mandibular specimens exhibit significantly more variation in several corpus size and shape variables when compared to extant great apes, modern humans, and extinct fossil hominin taxa (Skinner et al., 2006; but see Rightmire et al., 2008). Likewise, Martinón-Torres et al. (2008), in their descriptive and comparative study of Georgian teeth, suggest that the observed differences among the dental remains may indicate the presence of two distinct paleodemes at Dmanisi. Therefore, the results of these analyses, as well as the unclear geo- 
logical context associated with the hominin fossils, leave the interpretation of taxonomic homogeneity among the Georgian specimens in doubt.

Teeth are a valuable source of information for examining hominin morphological variation given that they develop early in life and change later only by breakage and wear, not remodeling, and thus their morphology expresses genetic information more directly than do other parts of the skeleton (Kieser, 1990; Brown and Walker, 1993; Henke, 1998; Gómez-Robles et al., 2007). Therefore, in this paper the hominin dental remains from Dmanisi are further analyzed to help determine whether the variation present in the Georgian assemblage likely reflects interspecific or intraspecific variation. The null hypothesis is that all the Georgian individuals represent one population and can therefore be subsumed within a single species. The degree of metric variation in the Dmanisi teeth was compared to that seen in reference samples of gorillas, chimpanzees, and modern humans using randomization methods. Comparisons were also made between the variation observed in the Georgian sample and that of Paranthropus boisei.

\section{Materials and Methods}

\section{Samples}

The Dmanisi dental sample utilized in this study includes the teeth associated with three mandibles and two crania, belonging to three individuals. The first individual consists of the D211 mandibular corpus with complete and little worn dentition, and the D2282 partial cranium, which retains the right $\mathrm{P}^{4}-\mathrm{M}^{1}$ and left $\mathrm{M}^{1}-\mathrm{M}^{2}$. The second individual is represented by the reasonably complete D2600 mandible with severely worn teeth, including the $\mathrm{I}_{1}-\mathrm{P}_{3}$ on both sides, $\mathrm{M}_{1}-\mathrm{M}_{3}$ on the right, and $\mathrm{M}_{2}-\mathrm{M}_{3}$ on the left. The last individual consists of the well-preserved D2735 mandible with slightly worn teeth including $\mathrm{P}_{3}-\mathrm{M}_{2}$ antimeres, the largely complete D2700 cranium preserving in situ the right $\mathrm{M}^{1}-\mathrm{M}^{2}$ and the left $\mathrm{P}^{4}$ and $\mathrm{M}^{2}$, as well as 12 isolated but associated teeth (Table 1). Data on the Dmanisi teeth were collected from the original specimens housed in the Georgian National Museum in Tbilisi, Georgia.

The comparative material used to assess variation within the Dmanisi sample consists of three extant, large-bodied hominine species: Pan troglodytes troglodytes, Gorilla gorilla gorilla, and Homo sapiens. The author collected dental data for all three samples from the Hamann-Todd Collection housed at the Cleveland Museum of Natural History. The modern human sample consists of African-American individuals drawn from this collection. The sample sizes for each dental dimension in each hominine species ranges from 37 to 50 individuals, with relatively equal numbers of males and females (Table 2). The comparative samples were chosen because they are the closest extant phylogenetic relatives of fossil hominins.

In addition to living hominines, Paranthropus boisei (sensu stricto) was included as a comparative fossil sample because its taxonomy is generally not contentious (Lockwood, 1999; Lockwood et al., 2000; Wood and Constantino, 2007; but see Groves, 1989). In addition, presumed members of both sexes have been collected, and the degree of dimorphism is
Table 1. Dmanisi dental sample

\begin{tabular}{|c|c|}
\hline Specimen & Description \\
\hline \multicolumn{2}{|c|}{ D211/D2282 skull } \\
\hline D211 & Mandibular corpus with right $I_{1}-M_{3}$ and left $I_{1}-M_{3}$ \\
\hline D2282 & Partial cranium with right $\mathrm{P}^{4}-\mathrm{M}^{1}$ and left $\mathrm{M}^{1}-\mathrm{M}^{2}$ \\
\hline D2600 & Mandible with right $\mathrm{I}_{1}-\mathrm{P}_{3}, \mathrm{M}_{1}-\mathrm{M}_{3}$ and left $\mathrm{I}_{1}-\mathrm{P}_{3}, \mathrm{M}_{2}-\mathrm{M}$ \\
\hline \multicolumn{2}{|c|}{ D2735/D2700 skull } \\
\hline D2735 & Mandible with right $\mathrm{P}_{3}-\mathrm{M}_{2}$ and left $\mathrm{P}_{3}-\mathrm{M}_{2}$ \\
\hline D2700 & Cranium with right $\mathrm{M}^{1}-\mathrm{M}^{\frac{2}{2}}$ and left $\mathrm{P}^{4}, \mathrm{M}^{\frac{2}{2}}$ \\
\hline D2677 & Left I ${ }^{2}$ \\
\hline D2678 & Right $\mathrm{C}_{1}$ \\
\hline D2710 & Left $\mathrm{M}^{1}$ \\
\hline D2711 & Right $\mathrm{M}^{3}$ \\
\hline D2719 & Right $\mathrm{P}^{4}$ \\
\hline D2720 & Left $\mathrm{M}^{3}$ \\
\hline D2723 & Left $\mathrm{C}_{1}$ \\
\hline D2732 & Right $C^{1}$ \\
\hline $\mathrm{D} 2736$ & Right $\mathrm{I}^{1}$ \\
\hline D2854 & Right $\mathrm{I}_{2}$ \\
\hline D3672 & Right $\mathrm{P}^{3}$ \\
\hline D3698 & Left $\mathrm{I}_{2}$ \\
\hline
\end{tabular}

probably high if the hypodigm is considered one species (Wood, 1991b; Lockwood, 1999; Lockwood et al., 2000). This fossil taxon is also useful for assessing variation in the Dmanisi sample because both groups have orthognathic faces and relatively small canines, which distinguish hominins from non-human apes (Wood, 1991b). Therefore, this sample provides important measures of the kinds of variation that can be expected to characterize an early hominin species. The composition of the $P$. boisei sample was modeled after that used by Wood et al. (1994). This sample was chosen to be as temporally and spatially restricted as possible, while maintaining a sufficient sample size, owing to the limited time depth and geographical range of the Dmanisi hominins. The specimens come from the Koobi Fora region and derive from deposits dated between 1.79 and 1.49 myr (Table 3). All Paranthropus data were obtained from published descriptions (Leakey and Walker, 1988; Wood, 1991a).

\section{Measurements}

The dental data evaluated in the randomization analyses (see below) includes buccolingual (BL) dimensions of many tooth classes, as well as corrected mesiodistal diameters $(\mathrm{MD}(\mathrm{C}))$ and measured crown areas (MCA) of the maxillary and mandibular postcanine teeth. Buccolingual diameters were taken with sliding calipers according to the methods outlined by Wood (1991a). For the postcanine teeth, mesiodistal diameters corrected for interproximal wear and measured crown areas were taken from standardized occlusal photographs following the methods outlined in previous studies (Wood and Abbott, 1983; Wood et al., 1983; Wood and Uytterschaut, 1987; Wood and Engleman, 1988; Bailey, 2004) with some modifications in image processing. Scaled photographs of occlusal surfaces were taken for individual teeth using a Nikon Coolpix 4300 digital camera with macro capabilities. The camera was mounted on a tripod and a level was used to ensure a consistent camera angle. Each tooth was positioned so that the plane of the cervical line was perpendicular to the optical axis of the camera. The tooth was 
Table 2. Sample statistics for the extant hominine reference taxa $\mathrm{a}^{\mathrm{a}}$

\begin{tabular}{|c|c|c|c|c|c|c|c|c|c|c|c|c|c|c|c|c|}
\hline & \multicolumn{5}{|c|}{ Homo sapiens } & \multicolumn{5}{|c|}{ Pan troglodytes } & \multicolumn{5}{|c|}{ Gorilla gorilla } \\
\hline & & $\mathrm{N}$ & Mean & $\mathrm{SD}$ & Range & $\mathrm{CV}$ & $\mathrm{N}$ & Mean & SD & Range & $\mathrm{CV}$ & $\mathrm{N}$ & Mean & SD & Range & $\mathrm{CV}$ \\
\hline \multirow[t]{3}{*}{$\mathrm{I}_{2} \mathrm{BL}$} & M & 23 & 6.7 & 0.61 & & 9.03 & 19 & 9.8 & 0.53 & & & 16 & 10.3 & 0.70 & $9.1-11.5$ & 6.74 \\
\hline & $\mathrm{F}$ & 20 & 6.3 & 0.33 & & & 22 & 9.0 & 0.66 & & & 22 & 9.6 & 0.77 & & 8.01 \\
\hline & $\mathrm{C}$ & 43 & 6.5 & 0.52 & $5.8-8.5$ & 8.03 & 41 & 9.4 & 0.73 & $7.9-10.8$ & 7.82 & 38 & 9.9 & 0.82 & $8.2-11.5$ & 8.31 \\
\hline \multirow[t]{3}{*}{$\mathrm{C}_{1} \mathrm{BL}$} & M & 23 & 8.2 & 0.60 & $7.3-9.9$ & 7.27 & 22 & 13.3 & 1.26 & $11.0-16.8$ & 9.47 & 21 & 17.8 & 1.14 & $15.4-19.6$ & 6.38 \\
\hline & $\mathrm{F}$ & 20 & 7.6 & 0.53 & $6.6-8.1$ & 6.91 & 22 & 10.2 & 1.32 & $8.0-13.0$ & 12.91 & 22 & 13.1 & 1.11 & $9.9-14.5$ & 8.51 \\
\hline & $\mathrm{C}$ & 43 & 8.0 & 0.64 & $6.6-c$ & 8.03 & 44 & 11.7 & 2.00 & & 17.00 & 43 & 15.4 & 2.65 & & 17.19 \\
\hline \multirow[t]{3}{*}{$\mathrm{P}_{3} \mathrm{MD}(\mathrm{C})$} & M & 24 & 7.8 & 0.48 & $7.0-8.6$ & & 20 & 11.2 & 0.61 & $10.2-12.5$ & & 22 & 16.6 & 1.11 & $14.5-18.5$ & 6.64 \\
\hline & $\mathrm{F}$ & 25 & 7.6 & 0.46 & $7.0-8.8$ & 6.02 & 24 & 10.9 & 0.75 & $9.7-12.6$ & & 23 & 14.6 & 0.54 & $13.6-15.7$ & 3.67 \\
\hline & $\mathrm{C}$ & 49 & 7.7 & 0.47 & $7.0-8.8$ & 6.12 & 44 & 11.0 & 0.70 & & & 45 & 15.6 & 1.34 & & 8.62 \\
\hline \multirow[t]{3}{*}{$\mathrm{P}_{3} \mathrm{BL}$} & M & 24 & 8.6 & 0.57 & $7.7-10.0$ & 6.55 & 20 & 8.1 & 0.48 & $7.3-9.0$ & 5.91 & 22 & 11.6 & 1.36 & $10.0-16.1$ & 11.72 \\
\hline & $\mathrm{F}$ & 25 & 8.2 & 0.53 & 6.9-9.2 & 6.52 & 24 & 7.5 & 0.57 & & 7.54 & 23 & 10.3 & 0.66 & & 6.39 \\
\hline & $\mathrm{C}$ & 49 & 8.4 & 0.60 & $6.9-10.0$ & 7.11 & 44 & 7.8 & 0.60 & 6.7 & & 45 & 11.0 & 1.23 & $9.2-16.1$ & 11.21 \\
\hline \multirow[t]{3}{*}{$\mathrm{P}_{3} \mathrm{MCA}$} & $\mathrm{M}$ & 23 & 48.9 & 6.57 & $39.8-65.9$ & 13.45 & 20 & 68.5 & 6.68 & $60.3-88.8$ & & 22 & & 20.19 & & \\
\hline & $\mathrm{F}$ & 24 & 45.0 & 5.07 & $36.9-55.9$ & 11.27 & 23 & 64.4 & 8.82 & $52.4-82.9$ & 13.69 & 23 & 119.8 & 10.91 & $102.9-141.5$ & 9.11 \\
\hline & $\mathrm{C}$ & 47 & 46.9 & 6.11 & $36.9-6$ & & 43 & 66.3 & 8.07 & & & 45 & & & & 17.15 \\
\hline $\mathrm{P}_{4} \mathrm{MD}(\mathrm{C})$ & M & 24 & 8.0 & 0.46 & $7.3-8.6$ & & 24 & & 0.55 & & & 25 & 12.0 & 0.96 & & 8.05 \\
\hline & $\mathrm{F}$ & 23 & 7.7 & 0.42 & $6.9-8.8$ & 5.51 & 24 & 8.0 & 0.38 & & & 25 & 11.5 & 0.55 & & 4.81 \\
\hline & $\mathrm{C}$ & 47 & & 0.47 & & & & & & & & & & & & 6.95 \\
\hline $\mathrm{P}_{4} \mathrm{BL}$ & M & 24 & 9.0 & 0.62 & $7.6-10.1$ & 6.94 & 24 & 9.4 & 0.67 & -11.3 & 7. & 25 & 13.2 & 1.19 & & 8.98 \\
\hline & $\mathrm{F}$ & 23 & & & & & & & & & & & & & & 6.30 \\
\hline & $\mathrm{C}$ & 47 & 8.7 & 0.61 & $7.6-10.1$ & 7.01 & 48 & 9.0 & 0.76 & $7.5-11.3$ & 8.46 & 50 & 12.8 & 1.09 & 10.9 & 8.55 \\
\hline $\mathrm{P}_{4} \mathrm{MCA}$ & M & 24 & 54.1 & 6.18 & & & 24 & 62.3 & 7.14 & & & 25 & 126.4 & & & \\
\hline & $\mathrm{F}$ & 23 & 49.1 & 4.82 & $42.6-61.8$ & 9.83 & 24 & 55.9 & 5.37 & -67.4 & & 25 & 2.8 & & $92.2-$ & 9.42 \\
\hline & $\mathrm{C}$ & 47 & 51.6 & 6.05 & & & 48 & 59.1 & 7.03 & & & 50 & & & & \\
\hline $\mathrm{M}_{1} \mathrm{MD}(\mathrm{C})$ & M & 20 & 11.9 & 0.50 & $11.0-13.3$ & & 22 & & 0.52 & & & & & & & \\
\hline & $\mathrm{F}$ & 23 & 11.7 & 0.46 & & 3.9 & 25 & 11.1 & 0.62 & & & & & & & \\
\hline & $\mathrm{C}$ & 43 & 11.8 & 0.49 & & & & & & & & & & & & \\
\hline $\mathrm{M}_{1} \mathrm{BL}$ & M & 20 & 10.8 & 0.47 & & & 23 & 10.0 & 0.65 & & & & 13.7 & & & 6.43 \\
\hline & $\mathrm{F}$ & 23 & & & & & & & & & & & & & & \\
\hline & $\mathrm{C}$ & 43 & 10.6 & 0.53 & $9.4-12.0$ & 5.00 & & 9.8 & 0.63 & & & & 13.4 & 0.84 & & \\
\hline $\mathrm{M}_{1} \mathrm{MCA}$ & M & 20 & & & & & 22 & & & & & & & & & \\
\hline & $\mathrm{F}$ & 23 & 99.3 & 8.08 & $80.8-113.4$ & 8.14 & 25 & 90.2 & 9.35 & 5.8 & & 23 & & & $132.7-19$ & 8.17 \\
\hline & $\mathrm{C}$ & 43 & 101.4 & 8.07 & $80.8-123.5$ & & 4 & 92.9 & 9.59 & & & 47 & 174.0 & & & 10.67 \\
\hline $\mathrm{M}_{2} \mathrm{MD}(\mathrm{C})$ & M & 19 & & 0.58 & $10.8-13.1$ & & 25 & 12.0 & 0.54 & & & 2 & 18.3 & & & 6.36 \\
\hline & $\mathrm{F}$ & 23 & 11.5 & & & & 25 & & & & & & & & & 4.26 \\
\hline & $\mathrm{C}$ & 42 & 11.6 & 0.54 & & & 5 & 11.7 & 0.59 & & & & 17.7 & & & \\
\hline $\mathrm{M}_{2} \mathrm{BL}$ & M & 19 & 11.0 & 0.54 & $10.2-12.2$ & 4.8 & 25 & 10.9 & 0.71 & & & 24 & 15.7 & 0.99 & & 6.30 \\
\hline & $\mathrm{F}$ & 23 & & & & & & & & & & 24 & & & & \\
\hline & $\mathrm{C}$ & 42 & & 0.51 & $9.9-12.2$ & & & 10.6 & 1.75 & & & 48 & 15.1 & 1.02 & & 6.77 \\
\hline $\mathrm{M}_{2} \mathrm{MCA}$ & M & 19 & 103.8 & 7.56 & $93.5-122.8$ & & 25 & & 12.05 & & & 24 & 233.1 & 27.75 & $183.2-28$ & 11.91 \\
\hline & $\mathrm{F}$ & 23 & & 8.20 & $79.5-112.6$ & & 25 & & 9.83 & & & 24 & & & & 7.57 \\
\hline & $\mathrm{C}$ & 42 & 100.8 & 8.27 & & & & & & & & & & & & \\
\hline $\mathrm{M}_{3} \mathrm{MD}(\mathrm{C})$ & $\mathrm{M}$ & 19 & 11.8 & 0.82 & $10.5-13.4$ & 6.96 & 21 & 11.4 & 0.55 & $10.6-12.6$ & & 22 & 18.0 & 1.27 & $15.9-20$ & 7.05 \\
\hline & $\mathrm{F}$ & 20 & & & & & 21 & & & & & 21 & & & & 5.32 \\
\hline & $\mathrm{C}$ & 39 & & 0.94 & & & & 11.1 & 0.62 & & & 43 & 17.4 & 1.29 & & 7.42 \\
\hline $\mathrm{M}_{3} \mathrm{BL}$ & M & 19 & 10.9 & 0.63 & $9.9-12.1$ & 5.80 & 21 & 10.5 & 0.61 & $9.1-11.6$ & 5.8 & 22 & 15.3 & 1.20 & $12.9-17.8$ & 7.88 \\
\hline & $\mathrm{F}$ & 20 & & & & & & & & & & & & & & \\
\hline & $\mathrm{C}$ & 39 & 10.8 & 0.59 & $9.5-12.1$ & 5.43 & 42 & 10.1 & 0.68 & $8.7-11.6$ & & 43 & 14.8 & 1.17 & $11.5-17.8$ & 7.92 \\
\hline $\mathrm{M}_{3} \mathrm{MCA}$ & M & 18 & 101.8 & 10.77 & $83.2-118.1$ & 10.57 & 21 & & 9.43 & $81.0-117.5$ & & 22 & 216.7 & 29.09 & $162.7-262.3$ & 13.42 \\
\hline & $\mathrm{F}$ & 20 & & 12.08 & $72.5-121.5$ & 2.64 & 21 & & & & & 21 & & 17.62 & & 9.35 \\
\hline & $\mathrm{C}$ & 38 & 98.5 & 11.76 & $72.5-121.5$ & 11.93 & 42 & 94.0 & 10.86 & $73.1-117.5$ & 11.55 & 43 & 202.9 & 27.85 & $143.1-262.3$ & 13.72 \\
\hline $\mathrm{P}^{4} \mathrm{MD}(\mathrm{C})$ & M & 22 & & 0.45 & $6.5-7.8$ & & 20 & 7.6 & 0.63 & & & 23 & 11.3 & 0.77 & 9.9-12.6 & 6.82 \\
\hline & $\mathrm{F}$ & 21 & & & & & 25 & & & & & & 10.8 & 0.62 & & \\
\hline & $\mathrm{C}$ & 43 & 7.2 & 0.45 & $6.3-8.4$ & 6.20 & 45 & 7.5 & 0.57 & $6.3-8.9$ & 7.63 & 48 & 11.0 & 0.74 & $9.5-12.6$ & 6.74 \\
\hline $\mathrm{P}^{4} \mathrm{BL}$ & M & 22 & 9.8 & 0.51 & $9.1-10.8$ & 5.16 & 20 & 10.4 & 0.80 & $8.5-11.9$ & 7.77 & 23 & 14.9 & 0.97 & $12.9-16.4$ & 6.54 \\
\hline & $\mathrm{F}$ & 22 & & & $8.3-10.3$ & & 25 & 10.0 & & $9.3-11.5$ & & 25 & 14.1 & 0.59 & $12.8-15.2$ & 4.21 \\
\hline & $\mathrm{C}$ & 44 & 9.7 & 0.51 & $8.3-10.8$ & 5.28 & 45 & 10.1 & 0.70 & $8.5-11.9$ & 6.91 & 48 & 14.5 & 0.89 & $12.8-16.4$ & 6.13 \\
\hline $\mathrm{P}^{4} \mathrm{MCA}$ & M & 21 & 54.0 & 5.02 & $47.7-63.9$ & & 20 & 62.7 & 9.13 & $44.7-81.4$ & 14.57 & 22 & 129.5 & 17.75 & $97.4-160.2$ & 13.71 \\
\hline & $\mathrm{F}$ & 22 & 53.8 & 7.18 & $41.6-68.4$ & 13.35 & 25 & 59.4 & 6.29 & $51.7-73.9$ & 10.59 & 24 & 118.3 & 12.82 & $94.3-147.0$ & 10.84 \\
\hline & $\mathrm{C}$ & 43 & 53.9 & 6.16 & $41.6-68.4$ & 11.41 & 45 & 60.8 & 7.77 & $44.7-81.4$ & 12.77 & 46 & 123.7 & 16.22 & $94.3-160.2$ & 13.11 \\
\hline $\mathrm{M}^{1} \mathrm{MD}(\mathrm{C})$ & $\mathrm{M}$ & 17 & 11.3 & 0.70 & $9.9-12.6$ & 6.16 & 22 & 10.8 & 0.63 & $9.7-12.3$ & 5.84 & 23 & 15.5 & 0.82 & $14.1-17.0$ & 5.25 \\
\hline & $\mathrm{F}$ & 23 & 11.0 & 0.54 & $9.7-12.0$ & 4.85 & 25 & 10.4 & 0.56 & $9.5-11.7$ & & 23 & 14.7 & 0.65 & $13.5-15.5$ & 4.41 \\
\hline & $\mathrm{C}$ & 40 & 11.2 & 0.62 & $9.7-12.6$ & 5.54 & 47 & 10.6 & 0.61 & $9.5-12.3$ & 5.75 & 46 & 15.1 & 0.85 & $13.5-17.0$ & 5.63 \\
\hline
\end{tabular}


Table 2. (continued)

\begin{tabular}{|c|c|c|c|c|c|c|c|c|c|c|c|c|c|c|c|c|}
\hline & & \multicolumn{5}{|c|}{ Homo sapiens } & \multicolumn{5}{|c|}{ Pan troglodytes } & \multicolumn{5}{|c|}{ Gorilla gorilla } \\
\hline & & $\mathrm{N}$ & Mean & $\mathrm{SD}$ & Range & $\mathrm{CV}$ & $\mathrm{N}$ & Mean & $\mathrm{SD}$ & Range & $\mathrm{CV}$ & $\mathrm{N}$ & Mean & SD & Range & $\mathrm{CV}$ \\
\hline \multirow[t]{3}{*}{$\mathrm{M}^{1} \mathrm{BL}$} & M & 17 & 11.7 & 0.56 & $10.9-13.1$ & 4.77 & 22 & 11.8 & 0.69 & $10.9-13.0$ & 5.4 & 23 & 15.5 & 1.00 & $13.9-17.2$ & 6.47 \\
\hline & $\mathrm{F}$ & 23 & 11.4 & 0.46 & $10.5-12.2$ & 4.02 & 25 & 11.2 & 0.73 & $10.0-12.7$ & 6.47 & 23 & 14.7 & 0.66 & $13.3-15.8$ & 4.50 \\
\hline & $\mathrm{C}$ & 40 & 11.5 & 0.51 & $10.5-13.1$ & 4.41 & 47 & 11.5 & 0.74 & $10.0-13.0$ & 6.48 & 46 & 15.1 & 0.93 & $13.3-17.2$ & 6.18 \\
\hline \multirow[t]{3}{*}{$\mathrm{M}^{1} \mathrm{MCA}$} & M & 16 & 103.2 & 11.19 & $85.8-128.4$ & 10.85 & 22 & 104.8 & 10.54 & $89.8-127.2$ & 10.06 & 22 & 183.9 & 20.00 & $142.4-218.9$ & 10.88 \\
\hline & $\mathrm{F}$ & 22 & 98.6 & 7.82 & $83.4-113.7$ & 7.93 & 25 & 96.6 & 10.04 & $78.2-114.8$ & 10.40 & 22 & 167.1 & 15.99 & $133.0-201.5$ & 9.57 \\
\hline & $\mathrm{C}$ & 38 & 100.5 & 9.52 & $83.4-128.4$ & 9.47 & 47 & 100.4 & 10.99 & $78.2-127.2$ & 10.94 & 44 & 175.5 & 198.1 & 133.0 & 11.29 \\
\hline \multirow[t]{3}{*}{$\mathrm{M}^{2} \mathrm{MD}(\mathrm{C})$} & M & 18 & 10.9 & 0.86 & $9.6-12.8$ & 7.84 & 22 & 11.0 & 0.63 & $9.9-12.5$ & 5.77 & 24 & 17.1 & 1.20 & $15.0-19.2$ & 7.02 \\
\hline & $\mathrm{F}$ & 25 & 10.9 & 0.65 & $9.7-12.5$ & 5.92 & 25 & 10.4 & 0.64 & $9.4-11.9$ & 6.14 & 25 & 15.8 & 0.76 & $14.2-16.8$ & 4.82 \\
\hline & $\mathrm{C}$ & 43 & 10.9 & 0.73 & $9.6-12.8$ & 6.71 & 47 & 10.7 & 0.69 & $9.4-12.5$ & & 49 & 16.4 & 1.17 & & 7.09 \\
\hline \multirow[t]{3}{*}{$\mathrm{M}^{2} \mathrm{BL}$} & M & 18 & 12.5 & 0.71 & $11.3-13.6$ & 5.66 & 22 & 1.2 & 0.79 & $10.9-13.6$ & & 24 & 16.5 & 1.02 & $14.7-18.8$ & 6.20 \\
\hline & $\mathrm{F}$ & 25 & 11.8 & 0.49 & $10.9-12.7$ & 4.17 & 25 & 11.5 & 0.71 & $10.4-13.0$ & 6.17 & 25 & 15.4 & 0.81 & $13.5-17.0$ & 5.26 \\
\hline & $\mathrm{C}$ & 43 & 12.1 & 0.66 & $10.9-13.6$ & 5.48 & 47 & 11.8 & 0.83 & $10.4-13.6$ & 6.96 & 49 & 15.9 & 1.06 & $13.5-18.8$ & 6.67 \\
\hline \multirow[t]{3}{*}{$\mathrm{M}^{2} \mathrm{MCA}$} & M & 16 & 103.1 & 12.00 & $84.4-126.4$ & 11.69 & 22 & 108.6 & 10.38 & $88.8-130.5$ & 9.56 & 23 & 211.3 & 28.11 & $161.9-272.9$ & 13.30 \\
\hline & $\mathrm{F}$ & 24 & 99.9 & 8.99 & $82.2-122.1$ & 9.00 & 25 & 98.4 & 10.87 & $77.2-118.4$ & 11.06 & 24 & 187.9 & 13.89 & $156.5-210.3$ & 7.39 \\
\hline & $\mathrm{C}$ & 40 & 101.1 & 10.27 & $82.2-126.4$ & 10.15 & 47 & 103.1 & 11.72 & $77.2-130.5$ & 11.37 & 47 & 199.4 & 24.80 & $156.5-272.9$ & 12.44 \\
\hline
\end{tabular}

${ }^{\mathrm{a}} \mathrm{MD}(\mathrm{C})=$ mesiodistal corrected; $\mathrm{BL}=$ buccolingual; $\mathrm{MCA}=$ measured crown area; $\mathrm{M}=$ males; $\mathrm{F}=$ females; $\mathrm{C}=\mathrm{combined}$ sex.

Table 3. Paranthropus boisei (sensu stricto) sample ${ }^{\mathrm{a}}$

\begin{tabular}{llc}
\hline \multicolumn{1}{c}{ Specimen } & \multicolumn{1}{c}{ Description } & Age $(\mathrm{myr})^{\mathrm{b}}$ \\
\hline KNM-ER 729 & Mandible & $1.49-1.55$ \\
KNM-ER 733 & Mandible/skull fragments & $1.49-1.55$ \\
KNM-ER 801 & Mandibular fragment & $1.56-1.60$ \\
KNM-ER 802 & Isolated teeth & $1.56-1.60$ \\
KNM-ER 810 & Mandibular fragment & 1.77 \\
KNM-ER 818 & Mandibular fragment & $1.55-1.65$ \\
KNM-ER 1171 & Isolated teeth & $1.56-1.60$ \\
KNM-ER 1467 & Isolated teeth & $1.49-1.55$ \\
KNM-ER 1509 & Isolated teeth & $1.56-1.60$ \\
KNM-ER 1804 & Maxillary fragment & 1.77 \\
KNM-ER 1816 & Mandibular fragments/teeth & $1.56-1.60$ \\
KNM-ER 1820 & Mandibular fragment & $1.67-1.70$ \\
KNM-ER 3230 & Mandible & $1.56-1.60$ \\
KNM-ER 3737 & Isolated teeth & $1.56-1.60$ \\
KNM-ER 3885 & Isolated tooth & $1.77-1.79$ \\
KNM-ER 3890 & Isolated tooth & $1.56-1.60$ \\
KNM-ER 5877 & Mandibular fragments & $1.49-1.55$ \\
KNM-ER 15930 & Mandibular fragment & 1.77 \\
KNM-ER 15940 & Isolated teeth & 1.77 \\
\hline
\end{tabular}

${ }^{a}$ Data from Wood (1991a); Leakey and Walker (1988).

${ }^{\mathrm{b}}$ Ages taken from Wood and Constantino (2007).

situated in the center of the image seen through the camera's LCD monitor to minimize parallax error (Bailey et al., 2004). A scale was included in each photograph and placed parallel to the tooth in the same horizontal plane as the occlusal surface. The digital photos were transferred to the computer, calibrated, and measured on-screen using Photoshop 7.0 software (C) Adobe Systems, Inc.). Each measurement was taken three times and the mean value recorded for the specimen. Intraobserver measurement error was consistently less than $1 \%$, comparable to other investigations of crown occlusal areas (e.g. Wood and Abbott, 1983; Bermúdez de Castro and Nicolás, 1995; Bromage et al., 1995; Bermúdez de Castro et al., 1999, 2001; Kondo and Townsend, 2006). The variables employed are limited to those that are present in at least two of the Georgian individuals. The mesiodistal and buccolingual measurements obtained for the Dmanisi teeth in this study (Table 4) do not differ considerably (generally less than $0.3 \mathrm{~mm}$ ) from those provided in earlier papers (Rightmire et al., 2006; MartinónTorres et al., 2008). However, several dimensions (such as those of the maxillary second molar and mandibular third premolar) do display more substantial variation - most likely due to differences in measurement technique, including corrections for interproximal wear, and observer error. When tooth antimeres are available, the average of both sides is used to represent the specimen in the randomization analyses.

\section{Statistical tests}

Systematic resampling (randomization) of skeletal dimensions is a powerful and useful method for assessing variation in small samples (Lockwood et al., 1996; Reno et al., 2003) and has been employed in a number of analyses concerning fossil hominins (e.g. Kramer et al., 1995; Richmond and Jungers, 1995; Grine et al., 1996; Lockwood et al., 1996, 2000; Arsuaga et al., 1997; Lorenzo et al., 1998, 2005; Aiello et al., 1999; Lockwood, 1999; Bermúdez de Castro et al., 2001; Silverman et al., 2001; Reno et al., 2003; Dobson, 2005; Villmoare, 2005; Skinner et al., 2006). In this study, exact randomization methodology (Manly, 1997) is used to evaluate the degree of variation in the Dmanisi dentition when only two individuals are available for analysis. This method involves computing all possible pairwise size ratios of metric variables (larger value divided by smaller value) in a comparative sample. A previous analysis, however, demonstrated that utilizing the entire sample available for a fossil assemblage presents a more conservative assessment of variation than that provided by pairwise comparisons using exact randomization, even when the fossil sample includes only three individuals (Lockwood et al., 1996). Therefore, for the remaining variables in which more than two Georgian specimens are available for study, bootstrapping methodology (Manly, 1997) is employed. This method consists of simulating 1000 random samples from a comparative taxon, keeping sample size comparable to the Georgian assemblage $(n=3)$. The maximum ratio (largest value divided by smallest value) of each random sample is then calculated. 
Table 4. Measurements (mm) of the Dmanisi dentition ${ }^{\mathrm{a}}$

\begin{tabular}{|c|c|c|c|c|c|c|}
\hline Variable & Side & D211 & D2282 & D2600 & $\mathrm{D} 2700^{\mathrm{b}}$ & $\mathrm{D} 2735^{\mathrm{c}}$ \\
\hline \multirow[t]{2}{*}{$\mathrm{P}^{4} \mathrm{MD}(\mathrm{C})$} & Right & - & 8.6 & - & 7.0 & - \\
\hline & Left & - & - & - & - & - \\
\hline \multirow[t]{2}{*}{$\mathrm{P}^{4} \mathrm{BL}$} & Right & - & 10.8 & - & 11.6 & - \\
\hline & Left & - & - & - & - & - \\
\hline \multirow[t]{2}{*}{$\mathrm{P}^{4} \mathrm{MCA}$} & Right & - & 71.7 & - & 65.5 & - \\
\hline & Left & - & - & - & - & - \\
\hline \multirow[t]{2}{*}{$\mathrm{M}^{1} \mathrm{MD}(\mathrm{C})$} & Right & - & 12.8 & - & 13.4 & - \\
\hline & Left & - & 12.7 & - & 13.1 & - \\
\hline \multirow[t]{2}{*}{$\mathrm{M}^{1} \mathrm{BL}$} & Right & - & 12.8 & - & 13.1 & - \\
\hline & Left & - & 12.9 & - & 13.0 & - \\
\hline \multirow[t]{2}{*}{$\mathrm{M}^{1} \mathrm{MCA}$} & Right & - & 135.0 & - & 144.0 & - \\
\hline & Left & - & 130.1 & - & 138.5 & - \\
\hline \multirow[t]{2}{*}{$\mathrm{M}^{2} \mathrm{MD}(\mathrm{C})$} & Right & - & - & - & 12.9 & - \\
\hline & Left & - & 13.0 & - & 13.1 & - \\
\hline \multirow[t]{2}{*}{$\mathrm{M}^{2} \mathrm{BL}$} & Right & - & - & - & 13.1 & - \\
\hline & Left & - & 12.4 & - & 13.1 & - \\
\hline \multirow[t]{2}{*}{$\mathrm{M}^{2} \mathrm{MCA}$} & Right & - & - & - & 136.1 & - \\
\hline & Left & - & 126.4 & - & 134.0 & - \\
\hline \multirow[t]{2}{*}{$\mathrm{I}_{2} \mathrm{BL}$} & Right & 6.4 & - & - & - & 7.2 \\
\hline & Left & 6.4 & - & - & - & 7.5 \\
\hline \multirow[t]{2}{*}{$\mathrm{C}_{1} \mathrm{BL}$} & Right & 8.2 & - & - & - & 9.2 \\
\hline & Left & 8.3 & - & - & - & 9.2 \\
\hline \multirow[t]{2}{*}{$\mathrm{P}_{3} \mathrm{MD}(\mathrm{C})$} & Right & 8.9 & - & $9.5^{\mathrm{d}}$ & - & 9.7 \\
\hline & Left & 9.1 & - & - & - & 9.9 \\
\hline \multirow[t]{2}{*}{$\mathrm{P}_{3} \mathrm{BL}$} & Right & 9.6 & - & $11.9^{\mathrm{d}}$ & - & 10.1 \\
\hline & Left & 9.4 & - & - & - & 10.1 \\
\hline \multirow[t]{2}{*}{$\mathrm{P}_{3} \mathrm{MCA}$} & Right & 63.6 & - & $85.4^{\mathrm{d}}$ & - & 73.0 \\
\hline & Left & 63.6 & - & - & - & 73.4 \\
\hline \multirow[t]{2}{*}{$\mathrm{P}_{4} \mathrm{MD}(\mathrm{C})$} & Right & 8.2 & - & - & - & 7.7 \\
\hline & Left & 8.2 & - & - & - & 7.8 \\
\hline \multirow[t]{2}{*}{$\mathrm{P}_{4} \mathrm{BL}$} & Right & 9.7 & - & - & - & 9.3 \\
\hline & Left & 9.7 & - & - & - & 9.3 \\
\hline \multirow[t]{2}{*}{$\mathrm{P}_{4} \mathrm{MCA}$} & Right & 65.6 & - & - & - & 60.0 \\
\hline & Left & 66.2 & - & - & - & 57.9 \\
\hline \multirow[t]{2}{*}{$\mathrm{M}_{1} \mathrm{MD}(\mathrm{C})$} & Right & 13.3 & - & - & - & 13.3 \\
\hline & Left & 13.4 & - & - & - & 13.2 \\
\hline \multirow[t]{2}{*}{$\mathrm{M}_{1} \mathrm{BL}$} & Right & 12.5 & - & - & - & 11.6 \\
\hline & Left & 12.4 & - & - & - & 11.2 \\
\hline $\mathrm{M}_{1} \mathrm{MCA}$ & Right & 133.3 & - & - & - & 132.0 \\
\hline & Left & 134.2 & - & - & - & 120.4 \\
\hline $\mathrm{M}_{2} \mathrm{MD}(\mathrm{C})$ & Right & 12.3 & - & 13.9 & - & 13.6 \\
\hline & Left & 12.2 & - & 13.8 & - & 13.2 \\
\hline $\mathrm{M}_{2} \mathrm{BL}$ & Right & 11.6 & - & 13.4 & - & 10.7 \\
\hline & Left & 11.6 & - & 13.0 & - & 10.5 \\
\hline $\mathrm{M}_{2} \mathrm{MCA}$ & Right & 122.1 & - & 157.0 & - & 120.0 \\
\hline & Left & 124.0 & - & 153.6 & - & 114.5 \\
\hline $\mathrm{M}_{3} \mathrm{MD}(\mathrm{C})$ & Right & 11.6 & - & 15.7 & - & - \\
\hline & Left & 11.2 & - & 15.0 & - & - \\
\hline $\mathrm{M}_{3} \mathrm{BL}$ & Right & 10.6 & - & 13.3 & - & - \\
\hline & Left & 10.5 & - & 12.5 & - & - \\
\hline $\mathrm{M}_{3} \mathrm{MCA}$ & Right & 98.7 & - & 176.3 & - & - \\
\hline & Left & 96.1 & - & 161.0 & - & - \\
\hline
\end{tabular}

${ }^{\text {a }} \mathrm{MD}(\mathrm{C})=$ mesiodistal corrected $\mathrm{BL}=$ buccolingual; $\mathrm{MCA}=$ measured crown area.

${ }^{\mathrm{b}}$ Includes specimens: D2710 (left $\mathrm{M}^{1}$ ) and D2719 (right $\mathrm{P}^{4}$ ). The left $\mathrm{P}^{4}$ is not included in the analyses as this tooth is pathologically deformed.

${ }^{c}$ Includes specimens: D2678 (right $\mathrm{C}_{1}$ ), D2723 (left $\mathrm{C}_{1}$ ), D2854 (right $\mathrm{I}_{2}$ ), and D3698 (left $\mathrm{I}_{2}$ ).

The severity of occlusal wear does not allow for an accurate estimation of crown dimensions in the unworn state, and thus measurements represent only minimum values.
For both resampling procedures, the maximum ratio for the Dmanisi sample is then compared against the distribution of ratios generated for the comparative sample to determine the likelihood of sampling a pair of specimens from a reference species that exhibit size differences greater than those present in the Dmanisi assemblage. If the result is a low probability $(P<0.05)$ in comparison to the species with a high degree of dimorphism (e.g. gorillas), this would suggest the presence of multiple species in the Georgian sample (Lockwood, 1999). Low probabilities when compared to less dimorphic chimpanzees and humans would suggest that size variation, and by inference sexual dimorphism, in the Dmanisi sample is higher than in those taxa (Lockwood, 1999).

Because multiple comparisons are made (26 for each reference taxon), the sequential Bonferroni correction (Holm, 1979; Rice, 1989) was used to protect against Type I errors and maintain an $\alpha$ level of 0.05 for each comparative group (across all 26 variables). However, within the biological sciences there is substantial debate concerning the application of the Bonferroni correction. A number of researchers note that there is no formal consensus for when, or how, adjustments for multiple testing are to be performed (e.g. Feise, 2002; Moran, 2003; Nakagawa, 2004), while others feel that the increase in Type II errors associated with this procedure is unacceptable (e.g. Rothman, 1990; Perneger, 1998; Moran, 2003; Nakagawa, 2004). In addition, some researchers feel that the Bonferroni correction is an inappropriate method for this type of data, because the separate dimensions do not constitute independent tests (Kramer et al., 1995; Lockwood, 1999; Lockwood et al., 2000). Therefore, significant values at unadjusted $0.05 \alpha$ levels are also reported.

The comparison of size variation at Dmanisi to that of $P$. boisei involved an assessment of whether, for each dental dimension, the maximum ratios found in this fossil sample exceeded that of the Georgian assemblage. These comparisons included a similar set of metric variables as that utilized in the randomization analyses with the extant hominine taxa; only maxillary P4 dimensions have been excluded, as the restricted australopithecine sample does not preserve the minimum of two individuals needed for comparison.

\section{Results}

The results of the randomization analyses for the Dmanisi dentition are presented in Table 5. In analyses that include only D211/D2282 and D2735/D2700, the Dmanisi dentition does not display excessive size variation compared with the distributions of the extant reference samples. Nearly all of the maxillary teeth analyzed show low levels of variation in which the probability of finding a maximum ratio in the comparative taxa greater than that of the Dmanisi sample is relatively high. Only one variable measured for the Dmanisi sample exceeds the size variation present in the highly dimorphic gorilla sample $\left[\mathrm{P}^{4} \mathrm{MD}(\mathrm{C}) ; P=0.025\right]$. However, this $P$-value is not significant after the sequential Bonferroni correction is applied. As for the mandibular teeth, no dental dimension is significantly more variable among the Dmanisi hominins than in the three reference samples.

Slightly different results are obtained when D2600 is included in the analyses along with D211 or both D211 and 
Table 5. Probabilities of obtaining maximum ratios in extant hominine samples greater than those that characterize the Dmanisi dentition ${ }^{\mathrm{a}}$

\begin{tabular}{|c|c|c|c|c|c|c|}
\hline Variable & Comparison & Ratio & $n$ & Humans & Chimpanzees & Gorillas \\
\hline $\mathrm{I}_{2} \mathrm{BL}$ & D2735/D211 & 1.156 & 2 & 0.152 & 0.205 & 0.180 \\
\hline $\mathrm{C}_{1} \mathrm{BL}$ & D2735/D211 & 1.115 & 2 & 0.327 & 0.658 & 0.653 \\
\hline $\mathrm{P}_{3} \mathrm{MD}(\mathrm{C})$ & D2735/D211 & 1.089 & 3 & 0.626 & 0.597 & 0.785 \\
\hline $\mathrm{P}_{3} \mathrm{BL}$ & D2600/D211 & 1.253 & 3 & 0.068 & 0.069 & 0.225 \\
\hline $\mathrm{P}_{3} \mathrm{MCA}$ & D2600/D211 & 1.343 & 3 & 0.206 & 0.208 & 0.430 \\
\hline $\mathrm{P}_{4} \mathrm{MD}(\mathrm{C})$ & D211/D2735 & 1.051 & 2 & 0.562 & 0.543 & 0.590 \\
\hline $\mathrm{P}_{4} \mathrm{BL}$ & D211/D2735 & 1.043 & 2 & 0.665 & 0.723 & 0.709 \\
\hline $\mathrm{P}_{4} \mathrm{MCA}$ & D211/D2735 & 1.117 & 2 & 0.500 & 0.428 & 0.553 \\
\hline $\mathrm{M}_{1} \mathrm{MD}(\mathrm{C})$ & D211/D2735 & 1.008 & 2 & 0.919 & 0.949 & 0.891 \\
\hline $\mathrm{M}_{1} \mathrm{BL}$ & D211/D2735 & 1.096 & 2 & 0.196 & 0.178 & 0.304 \\
\hline $\mathrm{M}_{1} \mathrm{MCA}$ & D211/D2735 & 1.060 & 2 & 0.585 & 0.700 & 0.675 \\
\hline $\mathrm{M}_{2} \mathrm{MD}(\mathrm{C})$ & D2600/D211 & 1.130 & 3 & 0.158 & 0.206 & 0.361 \\
\hline $\mathrm{M}_{2} \mathrm{BL}$ & D2600/D2735 & 1.245 & 3 & 0.000 & 0.077 & 0.053 \\
\hline $\mathrm{M}_{2} \mathrm{MCA}$ & D2600/D2735 & 1.324 & 3 & 0.050 & 0.181 & 0.233 \\
\hline $\mathrm{M}_{3} \mathrm{MD}(\mathrm{C})$ & D2600/D211 & 1.351 & 2 & 0.009 & 0.000 & 0.003 \\
\hline $\mathrm{M}_{3} \mathrm{BL}$ & D2600/D211 & 1.217 & 2 & 0.009 & 0.036 & 0.085 \\
\hline $\mathrm{M}_{3} \mathrm{MCA}$ & D2600/D211 & 1.749 & 2 & 0.000 & 0.000 & 0.003 \\
\hline $\mathrm{P}^{4} \mathrm{MD}(\mathrm{C})$ & $\mathrm{D} 2282 / \mathrm{D} 2700$ & 1.229 & 2 & 0.060 & 0.055 & 0.025 \\
\hline $\mathrm{P}^{4} \mathrm{BL}$ & D2700/D2282 & 1.074 & 2 & 0.344 & 0.455 & 0.410 \\
\hline $\mathrm{P}^{4} \mathrm{MCA}$ & D2282/D2700 & 1.095 & 2 & 0.550 & 0.597 & 0.634 \\
\hline $\mathrm{M}^{1} \mathrm{MD}(\mathrm{C})$ & D2700/D2282 & 1.039 & 2 & 0.622 & 0.637 & 0.651 \\
\hline $\mathrm{M}^{1} \mathrm{BL}$ & D2700/D2282 & 1.016 & 2 & 0.835 & 0.901 & 0.837 \\
\hline $\mathrm{M}^{1} \mathrm{MCA}$ & D2700/D2282 & 1.066 & 2 & 0.613 & 0.693 & 0.712 \\
\hline $\mathrm{M}^{2} \mathrm{MD}(\mathrm{C})$ & D2700/D2282 & 1.000 & 2 & 0.963 & 0.959 & 0.974 \\
\hline $\mathrm{M}^{2} \mathrm{BL}$ & D2700/D2282 & 1.056 & 2 & 0.489 & 0.600 & 0.581 \\
\hline $\mathrm{M}^{2} \mathrm{MCA}$ & D2700/D2282 & 1.069 & 2 & 0.656 & 0.694 & 0.673 \\
\hline
\end{tabular}

${ }^{\mathrm{a}} \mathrm{MD}(\mathrm{C})=$ mesiodistal corrected; $\mathrm{BL}=$ buccolingual; $\mathrm{MCA}=$ measured crown area. The maximum ratios for the Dmanis sample are calculated using the average value for tooth antimeres, when available. Boldface $P$-values indicate that Dmanisi ratios are significantly greater than those of the comparative samples $(P<0.05)$. Boldface and italic $P$-values indicate that Dmanisi ratios are significantly greater than those of the comparative samples after the sequential Bonferroni adjustment.

Table 6. Comparison of maximum ratios between Dmanisi and Paranthropus boisei ${ }^{\mathrm{a}}$

\begin{tabular}{|c|c|c|c|c|c|c|}
\hline \multirow[b]{2}{*}{ Variable } & \multicolumn{3}{|c|}{ Dmanisi } & \multicolumn{3}{|c|}{ Paranthropus boisei } \\
\hline & Comparison & Ratio & $n$ & Comparison & Ratio & $\mathrm{N}$ \\
\hline $\mathrm{I}_{2} \mathrm{BL}$ & D2735/D211 & 1.156 & 2 & KNM-ER 3230/ER 801 & 1.209 & 2 \\
\hline $\mathrm{C}_{1} \mathrm{BL}$ & D2735/D211 & 1.115 & 2 & KNM-ER 729/ER 3230 & 1.021 & 2 \\
\hline $\mathrm{P}_{3} \mathrm{MD}(\mathrm{C})$ & D2735/D211 & 1.089 & 3 & KNM-ER 729/ER 1816 & 1.120 & 3 \\
\hline $\mathrm{P}_{3} \mathrm{BL}$ & D2600/D211 & 1.253 & 3 & KNM-ER 3230/ER 1816 & 1.171 & 3 \\
\hline $\mathrm{P}_{3} \mathrm{MCA}$ & D2600/D211 & 1.343 & 3 & KNM-ER 729/ER 3230 & 1.024 & 2 \\
\hline $\mathrm{P}_{4} \mathrm{MD}(\mathrm{C})$ & D211/D2735 & 1.051 & 2 & KNM-ER 1171/ER 3885 & 1.287 & 8 \\
\hline $\mathrm{P}_{4} \mathrm{BL}$ & D211/D2735 & 1.043 & 2 & KNM-ER 3230/ER 1816 & 1.146 & 8 \\
\hline $\mathrm{P}_{4} \mathrm{MCA}$ & D211/D2735 & 1.117 & 2 & KNM-ER 3230/ER 802 & 1.220 & 7 \\
\hline $\mathrm{M}_{1} \mathrm{MD}(\mathrm{C})$ & D211/D2735 & 1.008 & 2 & KNM-ER 3230/ER 1820 & 1.111 & 8 \\
\hline $\mathrm{M}_{1} \mathrm{BL}$ & D211/D2735 & 1.096 & 2 & KNM-ER 729/ER 15930 & 1.250 & 8 \\
\hline $\mathrm{M}_{1} \mathrm{MCA}$ & D211/D2735 & 1.060 & 2 & KNM-ER 3230/ER 3890 & 1.197 & 7 \\
\hline $\mathrm{M}_{2} \mathrm{MD}(\mathrm{C})$ & D2600/D211 & 1.130 & 3 & KNM-ER 3230/ER 1816 & 1.185 & 5 \\
\hline $\mathrm{M}_{2} \mathrm{BL}$ & D2600/D2735 & 1.245 & 3 & KNM-ER 3230/ER 15930 & 1.297 & 6 \\
\hline $\mathrm{M}_{2} \mathrm{MCA}$ & D2600/D2735 & 1.324 & 3 & KNM-ER 3230/ER 1816 & 1.366 & 5 \\
\hline $\mathrm{M}_{3} \mathrm{MD}(\mathrm{C})$ & D2600/D211 & 1.351 & 2 & KNM-ER 5877/ER 810 & 1.441 & 8 \\
\hline $\mathrm{M}_{3} \mathrm{BL}$ & D2600/D211 & 1.217 & 2 & KNM-ER 5877/ER 15930 & 1.333 & 10 \\
\hline $\mathrm{M}_{3} \mathrm{MCA}$ & D2600/D211 & 1.749 & 2 & KNM-ER 729/ER 810 & 1.460 & 6 \\
\hline $\mathrm{M}^{1} \mathrm{MD}(\mathrm{C})$ & D2700/D2282 & 1.039 & 2 & KNM-ER 733/ER 1804 & 1.061 & 2 \\
\hline $\mathrm{M}^{1} \mathrm{BL}$ & D2700/D2282 & 1.016 & 2 & KNM-ER 733/ER 1804 & 1.024 & 2 \\
\hline $\mathrm{M}^{1} \mathrm{MCA}$ & D2700/D2282 & 1.066 & 2 & KNM-ER 733/ER 1804 & 1.005 & 2 \\
\hline $\mathrm{M}^{2} \mathrm{MD}(\mathrm{C})$ & D2700/D2282 & 1.000 & 2 & KNM-ER 1171/ER 1804 & 1.050 & 2 \\
\hline $\mathrm{M}^{2} \mathrm{BL}$ & D2700/D2282 & 1.056 & 2 & KNM-ER 1804/ER 1171 & 1.040 & 2 \\
\hline $\mathrm{M}^{2} \mathrm{MCA}$ & D2700/D2282 & 1.069 & 2 & KNM-ER 1804/ER 1171 & 1.071 & 2 \\
\hline
\end{tabular}

${ }^{\mathrm{a}} \mathrm{MD}(\mathrm{C})=$ mesiodistal corrected; $\mathrm{BL}=$ buccolingual; $\mathrm{MCA}=$ measured crown area. The maximum ratios are calculated using the average value for tooth antimeres, when available. Boldface values indicate that the maximum ratio of the Dmanisi dentition exceeds that found in any pairwise comparison in P. boisei. 
D2735. The maximum ratios of the Dmanisi teeth for third premolar and second molar dimensions are commonly exceeded in random samples of extant hominines. Of these eight dental dimensions analyzed in the Dmanisi sample, two display more variation than is present in modern humans $\left(\mathrm{M}_{2} \mathrm{BL}, \mathrm{M}_{2} \mathrm{MCA} ; P \leq 0.05\right)$, and only crown width $(P=0.000)$ is significant after the sequential Bonferroni correction is applied.

However, as the measurements of the third premolar recorded for D2600 represent only minimum values, the maximum ratios provided for the Georgian third premolars almost certainly underestimate the size variation among these hominins. In the Georgian dentition, the $\mathrm{M}_{3}$ appears to be the most variable tooth. All three dental dimensions of the Dmanisi assemblage have maximum ratios that are rarely, or never, exceeded in pairwise comparisons of either modern humans or chimpanzees $(P \leq 0.036)$. Crown length and area of the third molar are also more variable than in the gorilla sample $(P=0.003)$. The $P$-values for the gorilla sample are not significant, however, after the sequential Bonferroni adjustment.

The results of the comparison of maximum ratios for the Dmanisi and $P$. boisei samples are given in Table 6. These results indicate that there is a fair amount of size variation in the $P$. boisei sample. In relation to the Dmanisi assemblage, the $P$. boisei sample possesses larger maximum ratios for a majority of variables, including dimensions of the mandibular P4, M1, and M2. As with the Dmanisi assemblage, the $\mathrm{M}_{3}$ appears to be the most variable tooth in the $P$. boise $i$ sample. The maximum ratios for $P$. boisei exceed those of Dmanisi for $\mathrm{M}_{3}$ crown length and breadth diameters, although the Georgian sample is more variable for $\mathrm{M}_{3}$ crown area. In addition, the Dmanisi dentition possesses maximum ratios that exceed those of $P$. boisei for several mandibular canine and third premolar crown dimensions. For the maxillary teeth, the maximum ratios for the two fossil hominin samples are roughly equal for most dimensions.

\section{Discussion}

The results from the randomization analyses reveal that the Dmanisi sample is characterized by a lower level of maxillary dental size variation than all extant comparative taxa. Likewise, size variation in the mandibular dimensions of the Dmanisi dentition is exceeded in the comparative samples much of the time. As nearly all of these comparisons are between D211/D2282 and D2735/D2700, the results of the analyses provide evidence for the taxonomic homogeneity of these two individuals. This is consistent with a recent morphological analysis of the Dmanisi dental remains (Martinón-Torres et al., 2008), as well as earlier studies concerning the associated mandibles and crania (Vekua et al., 2002; Rightmire et al., 2006).

Interestingly, among the Dmanisi mandibular teeth a couple of $\mathrm{M}_{3}$ dimensions display significantly greater size variation (using unadjusted significance levels) compared to the highly dimorphic Gorilla sample. These comparisons include teeth associated with the large and somewhat distinct D2600 mandible. However, the results of the randomization analyses using Bonferroni-adjusted significance levels indi- cate that the size variation observed in the Dmanisi sample for all dental dimensions, including the third molar, is not significantly greater than in the gorilla sample, and thus provide no support for a multiple-species hypothesis. For the additional variables in which D2600 was included in the comparisons (such as $\mathrm{P}_{3}$ and $\mathrm{M}_{2}$ dimensions), the variation exhibited by the Dmanisi specimens is also not significant, supporting a single-taxon solution. However, the values recorded for D2600, particularly for the third premolar, are affected by occlusal wear, and as a result, the degree of variation among the Georgian hominins for this tooth is almost certainly underestimated. Therefore, when compared to extant reference taxa, the degree of metric variation within the Dmanisi dental sample provides equivocal evidence concerning the taxonomic association of D2600 with the other Georgian specimens.

The Dmanisi hominins also appear less variable than $P$. boisei, a fossil taxon whose integrity as a single species has been confirmed by a number of studies (e.g. Wood, 1991b; Silverman et al., 2001; Wood and Lieberman, 2001). On the whole, the $P$. boisei sample displays larger maximum ratios than does the Dmanisi assemblage. This includes ratios for several $\mathrm{M}_{2}$ and $\mathrm{M}_{3}$ dimensions that were significantly more variable compared to the extant reference taxa. These results suggest that the size variation within the Dmanisi dental sample, including that of the $\mathrm{M}_{3}$, is not excessive for a fossil hominin group dated to the Early Pleistocene. However, the high variability displayed by $P$. boisei may be due, in part, to the effects of time (Lockwood et al., 2000). Although the $P$. boisei sample was chosen to be as temporally and geographically restricted as possible, a time depth up to $250 \mathrm{ka}$ is associated with the specimens included in the size comparisons; and even a few tens of thousands of years may generate an additional source of variation in fossil collections (Pilbeam, 1978; Lieberman et al., 1988; Wood and Xu, 1991; Wood, 1993). Nonetheless, the diversity within the $P$. boisei sample employed in this study must reflect, to a certain extent, the considerable range of size variation previously observed for this taxon (e.g. Blumenberg and Lloyd, 1983; Wood, 1991b; Lockwood et al., 2000; Silverman et al., 2001; Moggi-Cecchi, 2003). Therefore, the metric size variation observed within the Dmanisi dental sample is insufficient to reject the null hypothesis of a single species, assuming that the variation displayed by the $P$. boisei sample sets an appropriate upper limit by which to judge the Georgian assemblage.

Although metric analyses provide valuable evidence regarding the taxonomic homogeneity of a fossil sample, a more robust evaluation also includes information concerning the level of morphological variation. However, the tooth crowns of D2600 are appreciably worn, prohibiting a comprehensive assessment of the morphological dental variation displayed by the Dmanisi hominins. Nonetheless, one morphological feature that can be observed in this specimen is mandibular premolar root form. The expression of premolar root form within the Dmanisi sample was among the features that prompted Gabunia and colleagues (Gabunia et al., $2002 b$ ) to question the taxonomic association of D2600 and D211. Among the Georgian specimens, the lower premolars of D211 are single-rooted, whereas in D2600 these teeth ex- 
hibit two completely separate roots (mesial and distal). In $\mathrm{D} 2735$, the $\mathrm{P}_{3}$ s have a Tomes' root form, while the $\mathrm{P}_{4} \mathrm{~s}$ are single-rooted (Macaluso, 2006). However, mandibular premolar root form among other early Homo groups is also quite variable, with expression varying from a single root, via Tomes' root form, to teeth with separate mesial and distal roots (Wood, 1991a, 1993, 1994; Antón, 2003; Kaifu et al., 2005). In addition, modern human populations are also polymorphic in mandibular premolar root form (Abbott, 1984; Eckhardt, 2003). Furthermore, a recent study of postcanine mandibular root form among modern humans has demonstrated that males with larger teeth have a significantly higher proportion of multi-rooted premolars (Shields, 2005). Wood (1993) also demonstrated that the $P_{3}$ roots of $P a n$ are somewhat sexually dimorphic, with females exhibiting a higher frequency of single-rooted teeth (46\%) compared to that of males $(20 \%)$. Assuming that these relationships also apply to Plio-Pleistocene Homo, the variation observed in the postcanine subocclusal morphology of the Dmanisi hominins may be attributed to sexual dimorphism. Therefore, based on these comparisons, it is not unreasonable to presume that the polymorphism in premolar root form within the Dmanisi sample is the result of normal intraspecific variation.

In summary, the majority of metric dimensions do not exhibit a significant level of variation compared to extant and extinct hominines. In addition, the evidence for interspecific variation among the Georgian $\mathrm{M}_{3}$ crowns and premolar roots is not conclusive. Therefore, the results presented above provide tentative support for the acceptance of the singlespecies hypothesis for the current dental sample. If it is accepted that all of the Dmanisi hominins, including the large D2600 mandible, belong to a single taxon, then sexual dimorphism is one explanation for the observed differences between specimens (Gabunia et al., 2002a; Lordkipanidze et al., 2006; Rightmire et al., 2008).

\section{Conclusions}

When the results of the randomization analyses and comparisons of premolar root form are considered, the case for taxonomic heterogeneity within the Georgian dental sample is finely balanced. For most variables, the range of size among the specimens from Dmanisi can be accommodated within models of dimorphism based on extant and extinct analogues. As the comparisons frequently incorporate D211/ D2282 and D2735/D2700, these specimens can be grouped together without reservation. This result is consistent with previous studies pertaining to the observable variation among the associated cranial and mandibular remains (Vekua et al., 2002; Macaluso et al., 2004; Rightmire et al., 2006). Whether the D2600 mandible should be included within this sample or considered distinct is perhaps more questionable as the dentition of this robust specimen differs from the other Georgian fossils in proportions of the distal cheek teeth and its premolar root form. Nonetheless, it is argued that the size range and variation in premolar root form expressed by the Dmanisi dental sample, including D2600, is presently insufficient to reject the null hypothesis of a single species.

\section{Acknowledgments}

This project was performed as part of research for a $\mathrm{Ph} . \mathrm{D}$. dissertation in the Department of Anthropology, Binghamton University (SUNY), under the thoughtful guidance of G.P. Rightmire. I thank D. Lordkipanidze for the invitation to study the dental remains and participate in the excavations at Dmanisi. I am grateful to the many individuals at the Georgian National Museum in Tbilisi who provided access to, and assistance with, the fossils examined during this research, in particular A. Vekua and T. Jashashvili. I also thank Y. Haile-Selassie and L. Jellema (Cleveland Museum of Natural History) for providing access to their collections and for their hospitality during my visit. This study was supported by grants from the L.S.B. Leakey Foundation and the National Science Foundation (BSC-0332769).

\section{References}

Abbott S.A. (1984) A comparative study of tooth root morphology in the great apes, modern man and early hominids. Dissertation, University of London.

Aiello L.C., Wood B.A., Key C., and Lewis M. (1999) Morphological and taxonomic affinities of the Olduvai Ulna (OH 36). American Journal of Physical Anthropology, 109: 89-110.

Antón S.C. (2003). Natural history of Homo erectus. Yearbook of Physical Anthropology, 46: 126-170.

Arsuaga J.L., Carretero J.M., Lorenzo C., Gracia A., Martínez I., Bermúdez de Castro J.M., and Carbonell E. (1997) Size variation in Middle Pleistocene humans. Science, 277: 1086-1088.

Bailey S.E. (2004) A morphometric analysis of maxillary molar crowns of Middle-Late Pleistocene hominins. Journal of Human Evolution, 57: 183-198.

Bailey S.E., Pilbrow V.C., and Wood B.A. (2004) Interobserver error involved in independent attempts to measure cusp base areas of Pan $\mathrm{M}^{1}$ s. Journal of Anatomy, 205: 323-331.

Bermúdez de Castro J.M. and Nicolás M.E. (1995) Posterior dental size reduction in hominids: the Atapuerca evidence. American Journal of Physical Anthropology, 96: 335-356.

Bermúdez de Castro J.M., Rosas A., and Nicolás M.E. (1999) Dental remains from Atapuerca-TD6 (Gran Dolina site, Burgos, Spain). Journal of Human Evolution, 37: 523-566.

Bermúdez de Castro J.M., Sarmiento S., Cunha E., Rosas A., and Bastir M. (2001) Dental size variation in the Atapuerca-SH Middle Pleistocene hominids. Journal of Human Evolution, 41: 195-209.

Blumenberg B. and Lloyd A.T. (1983) Australopithecus and the origin of the genus Homo: aspects of biometry and systematics with accompanying catalog of tooth metric data. BioSystems, 16: 127-167.

Bromage T.G., Schrenk F., and Zonneveld F.W. (1995) Paleoanthropology of the Malawi Rift: an early hominid mandible from the Chiwondo Beds, northern Malawi. Journal of Human Evolution, 28: 71-108.

Brown B. and Walker A. (1993) The dentition. In: Walker A. and Leakey R. (eds.), The Nariokotome Homo erectus Skeleton. Harvard University Press, Cambridge, MA, pp. 161-192.

Calvo-Rathert M., Goguitchaichvili A., Sologashvili D., Villalaín J.J., Bógalo M.F., Carrancho A., and Maissuradze G. (2008) New paleomagnetic data from the hominin bearing Dmanisi paleo-anthropologic site (southern Georgia, Caucasus). Quaternary Research, 69: 91-96.

de Lumley M.A., Bardintzeff J.M., Bienvenu P., Bilcot J.B., Flamenbaum G., Guy C., Jullien M., de Lumley H., Nabot J.P., Perrenoud C., Provitina O., and Tourasse M. (2008) Impact probable du volcanisme sur le décès des Hominidés de Dmanissi. Comptes-Rendus Palevol, 7: 61-79. 
Dobson S.D. (2005) Are the differences between Stw 431 (Australopithecus africanus) and A.L. 288-1 (A. afarensis) significant? Journal of Human Evolution, 49: 143-154.

Eckhardt R.B. (2003) Polymorphisms past and present. Human Biology, 75: 559-575.

Feise R.J. (2002) Do multiple outcome measures require p-value adjustment? BMC Medical Research Methodology, 2: 8.

Gabunia L. and Vekua A. (1995) A Plio-Pleistocene hominid from Dmanisi, East Georgia, Caucasus. Nature, 373: 509-512.

Gabunia L., Vekua A., Lordkipanidze D., Swisher C.C., Ferring R., Justus A., Nioradze M., Tvalchrelidze M., Antón S.C., Bosinski G., Joris O., de Lumley M.A., Majsuradze G., and Mouskelishvili A. (2000) Earliest Pleistocene hominid cranial remains from Dmanisi, Republic of Georgia: taxonomy, geological setting, and age. Science, 288: 1019-1025.

Gabunia L., Antón S.C., Lordkipanidze D., Vekua A., Justus A., and Swisher C.C. (2001) Dmanisi and dispersal. Evoluntionary Anthropology, 10: 158-170.

Gabunia L., de Lumley M.A., Vekua A., Lordkipanidze D., and de Lumley H. (2002a) Découvrte d'un nouvel hominidé à Dmanissi (Trancaucasie, Géorgie). Comptes-Rendus Palevol, 1: 243-253.

Gabunia L., Vekua A.K., de Lumley M.A., and Lordkipanidze D. (2002b) A new species of Homo represented by a fossil from the bottom part of the Pleistocene layer at Dmanisi, Georgia. Archaeology, Ethnology \& Anthropology of Eurasia, 4: 145152.

Gómez-Robles A., Martinón-Torres M., Bermúdez de Castro J.M., Margvelashvili A., Bastir M., Arsuaga J.L., Pérez-Pérez A., Estebaranz F., and Martínez L.M. (2007) A geometric morphometric analysis of hominin upper first molar shape. Journal of Human Evolution, 53: 272-285.

Grine F.E., Jungers W.L., and Schultz M. (1996) Phenetic affinities among early Homo crania from East and South Africa. Journal of Human Evolution, 30: 189-225.

Groves C.P. (1989) A theory of human and primate evolution. Oxford: Clarendon Press, Oxford.

Henke W. (1998) Current aspects of dental research in paleoanthropology. In: Alt K.W., Rösing F.W., and Teschler-Nicola M. (eds.), Dental Anthropology: Fundamentals, Limits, and Prospects. Springer-Verlag, Wien, pp. 179-200

Holm S. (1979) A simple sequentially rejective multiple test procedure. Scandinavian Journal of Statistics, 6: 65-70.

Kaifu Y., Aziz F., and Baba H. (2005) Hominid mandibular remains from Sangiran: 1952-1986 collection. American Journal of Physical Anthropology, 128: 497-519.

Kieser J.A. (1990) Human Adult Odontometrics. Cambridge University Press, Cambridge.

Kondo S. and Townsend G.C. (2006) Associations between Carabelli trait and cusp areas in human permanent maxillary first molars. American Journal of Physical Anthropology, 129: 196-203.

Kramer A., Donnelly S.M., Kidder J.H., Ousley S.D., and Olah S.M. (1995) Craniometric variation in large-bodied hominoids: testing the single-species hypothesis for Homo habilis. Journal of Human Evolution, 29: 443-462.

Leakey R.E.F. and Walker A.C. (1988) New Australopithecus boisei specimens from East and West Turkana, Kenya. American Journal of Physical Anthropology, 76: 1-24.

Lee S.H. (2005) Is variation in the cranial capacity of the Dmanisi sample too high to be from a single species? American Journal of Physical Anthropology, 127: 263-266.

Lieberman D.E., Pilbeam D.R., and Wood B.A. (1988) A probabilistic approach to the problem of sexual dimorphism in Homo habilis: a comparison of KNM-ER 1470 and KNM-ER 1813. Journal of Human Evolution, 17: 503-511.

Lockwood C.A. (1999) Sexual dimorphism in the face of Australopithecus africanus. American Journal of Physical Anthropology, 108: 97-127.

Lockwood C.A., Richmond B.G., Jungers W.L., and Kimbel W.H.
(1996) Randomization procedures and sexual dimorphism in Australopithecus afarensis. Journal of Human Evolution, 31: 537-548.

Lockwood C.A., Kimbel W.H., and Johanson D.C. (2000) Temporal trends and metric variation in the mandibles and dentition of Australopithecus afarensis. Journal of Human Evolution, 39: 23-55

Lordkipanidze D., Vekua A., Ferring C.R., Rightmire G.P., Agusti J., Kiladze G., Mouskelishvili A., Nioradze M., Ponce de León M.S., Tappen M., and Zollikofer C. (2005) The earliest toothless hominin skull. Nature, 434: 717-718.

Lordkipanidze D., Vekua A., Ferring C.R., Rightmire G.P., Zollikofer C., Ponce de Leon M., Agusti J., Kiladze G., Mouskelishvili A., Nioradze G., and Tappen M. (2006) A fourth hominin skull from Dmanisi, Georgia. Anatomical Record, 288A: 1146-1157.

Lordkipanidze D., Jashashvili T., Vekua A., Ponce de Leon M., Zollikofer C., Rightmire G.P., Pontzer H., Ferring C.R., Oms O., Tappen M., Buksianidze M., Agusti J., Kahlke R., Martinez-Navarro B., Mouskelishvili A., Nioradze M., and Rook L. (2007) Postcranial evidence from early Homo from Dmanisi, Georgia. Nature, 449: 305-310.

Lorenzo C., Carretero J.M., Arsuaga J.L., Gracia A., and Martinez I. (1998) Intrapopulational body size variation and cranial capacity variation in Middle Pleistocene humans: the Sima de los Huesos simple (Sierra de Atapuerca, Spain). American Journal of Physical Anthropology, 106: 19-34.

Lorenzo C., Martínez I., Arsuaga J.L., and Gracia A. (2005) Bootstrap method and the analysis of cranial capacity variation in the Dmanisi fossils and Homo ergaster. American Journal of Physical Anthropology, Suppl. 40: 140-141.

Macaluso P.J. (2006) Descriptions and comparative studies of the hominin dental remains from Dmanisi, Georgia: 1991-2002 Collections. Ph.D. Dissertation, Binghamton University.

Macaluso P.J., Hopwood D.E., Kiokis G., Malit N., Nevgloski A.J., Jr, McCausland Gaines J.B., and Lordkipanidze D. (2004) Cranial variation among the Plio-Pleistocene hominins from Dmanisi, Georgia. American Journal of Physical Anthropology, Suppl. 38: 143.

Manly B.F.J. (1997) Randomization, Bootstrap and Monte Carlo Methods in Biology, Second Edition. Chapman \& Hall, London.

Martinón-Torres M., Bermúdez de Castro J.M., Gómez-Robles A., Margvelashvili A., Prado L., Lordkipanidze D., and Vekua A. (2008) Dental remains from Dmanisi (Republic of Georgia): morphological analysis and comparative study. Journal of Human Evolution, 55: 249-273.

Moggi-Cecchi J. (2003) The elusive 'second species' in Sterkfontein member 4: the dental metrical evidence. South African Journal of Science, 99: 268-270.

Moran M.D. (2003) Arguments for rejecting the sequential Bonferroni in ecological studies. Oikos, 100: 403-405.

Nakagawa S. (2004) A farewell to Bonferroni: the problems of low statistical power and publication bias. Behavioral Ecology, 15: 1044-1045

Perneger T.V. (1998) What's wrong with Bonferroni adjustments. British Medical Journal, 316: 1236-1238.

Pilbeam D.R. (1978) Recognizing specific diversity in heterogeneous fossil samples. In: Jolly C. (ed.), Early Hominids of Africa. Duckworth, London, pp. 505-515.

Reno P.L., Meindl R.S., McCollum M.A., and Lovejoy C.O (2003) Sexual dimorphism in Australopithecus afarensis was similar to that of modern humans. Proceedings of the National Academy of Sciences USA, 100: 9404-9409.

Rice W.R. (1989) Analyzing tables of statistical tests. Evolution, 43: 223-225.

Richmond B. and Jungers W.L. (1995) Size variation and sexual dimorphism in Australopithecus afarensis and living hominoids. Journal of Human Evolution, 29: 229-245.

Rightmire G.P., Lordkipanidze D., and Vekua A. (2006) Anatomi- 
cal descriptions, comparative studies and evolutionary significance of the hominin skulls from Dmanisi, Republic of Georgia. Journal of Human Evolution, 50: 115-141.

Rightmire G.P., Van Arsdale A.P., and Lordkipanidze D. (2008) Variation in the mandibles from Dmanisi, Georgia. Journal of Human Evolution, 54: 904-908.

Rothman K.J. (1990) No adjustments are needed for multiple comparisons. Epidemiology, 1: 43-46.

Schwartz J.H. (2000) Taxonomy of the Dmanisi crania. Science, 289: 55.

Schwartz J.H. and Tattersall I. (2003) The Human Fossil Record. Vol. 2: Craniodental Morphology of Genus Homo (Africa and Asia). Wiley-Liss, New York.

Shields E.D. (2005) Mandibular premolar and second molar root morphological variation in modern humans: what root number can tell us about tooth morphologenesis. American Journal of Physical Anthropology, 128: 299-311.

Silverman N., Richmond B., and Wood B. (2001) Testing the taxonomic integrity of Paranthropus boisei sensu stricto. American Journal of Physical Anthropology, 115: 167-178.

Skinner M.M., Gordon A.D., and Collard N.J. (2006) Mandibular size and shape variation in the hominins at Dmanisi, Republic of Georgia. Journal of Human Evolution, 51: 36-49.

Vekua A., Lordkipanidze D., Rightmire G.P., Agusti J., Ferring R., Maisuradze G., Mouskhelishvili A., Nioradze M., Ponce de León M., Tappen M., Tvalchrelidze M., and Zollikofer C. (2002) A new skull of early Homo from Dmanisi, Georgia. Science, 297: 85-89.

Villmoare B.A. (2005) Metric and non-metric randomization methods, geographic variation, and the single-species hypothesis for Asian and African Homo erectus. Journal of Human Evolution, 49: 680-701.

Wood B.A. (1991a) Koobi Fora Research Project, Vol. 4: Hominid Cranial Remains from Koobi Fora. Clarendon Press, Oxford.

Wood B.A. (1991b) A palaeontological model for determining the limits of early hominid taxonomic variability. Palaeontologica Africana, 28: 71-77.

Wood B. (1993) Early Homo: how many species? In: Kimbel W.H. and Martin B. (eds.), Species, Species Concepts, and Primate Evolution. Plenum Press, New York, pp. 484-522.

Wood B.A. (1994) Taxonomy and evolutionary relationships of Homo erectus. Courier Forschungsinstitut Senckenberg, 171: $159-165$.

Wood B.A. and Abbott S.A. (1983) Analysis of the dental morphology of Plio-Pleistocene hominids I. Mandibular molars: crown area measurements and morphological traits. Journal of Anatomy, 136: 197-219.

Wood B. and Constantino P. (2007) Paranthropus boisei: fifty years of evidence and analysis. Yearbook of Physical Anthropology, 50: 106-132.

Wood B.A. and Engleman C.A. (1988) Analysis of the dental morphology of Plio-Pleistocene hominids V. Maxillary postcanine tooth morphology. Journal of Anatomy, 161: 1-35.

Wood B.A. and Lieberman D.E. (2001) Craniodental variation in Paranthropus boisei: a developmental and functional perspective. American Journal of Physical Anthropology, 116: $13-25$.

Wood B.A. and Uytterschaut H. (1987) Analysis of the dental morphology of Plio-Pleistocene hominids III. Mandibular premolar crowns. Journal of Anatomy, 154: 121-156.

Wood B.A. and Xu Q. (1991) Variation in the Lufeng dental remains. Journal of Human Evolution, 20: 291-311.

Wood B.A., Abbott S.A., and Graham S.H. (1983) Analysis of the dental morphology of Plio-Pleistocene hominids II. Mandibular molars-study of cusp areas, fissure pattern and cross sectional shape of the crown. Journal of Anatomy, 137: 287-314.

Wood B.A., Wood C., and Kongisberg L. (1994) Paranthropus boisei: an example of evolutionary stasis? American Journal of Physical Anthropology, 95: 117-136. 